\title{
CATEGORIAS SÓCIO-PROFISSIONAIS, TITULAÇÃO ESCOLAR E DISPUTAS ELEITORAIS
}

\author{
Odaci Luiz Coradini
}

\begin{abstract}
RESUMO
O artigo expõe resultados da análise das relações entre recursos de posição social, investimentos financeiros em campanhas e resultados em disputas eleitorais de diferentes níveis. Foram incluídos os candidatos às eleições municipais de 2004 e gerais de 2006. No que tange aos recursos de posição social, foram examinadas particularmente as associações com a condição profissional e com a titulação escolar. Foram examinados também os efeitos da ocupação prévia de cargos eletivos. Conforme a hipótese geral perseguida, por um lado, ocorre um processo de concentração nas categorias ocupacionais que representam posição social mais alta e mais fortemente associada à titulação escolar mais valorizada na medida em que o cargo em disputa é hierarquicamente mais elevado. Além disso, nas disputas para cada cargo os efeitos desses recursos estão presentes nas chances de sucesso ou fracasso eleitoral. Por outro lado, além dos recursos associados à ocupação e ao grau de escolarização, na medida em que o cargo em disputa é mais elevado $e$ as chances de sucesso são mais altas, também cresce o peso do "carisma de função" decorrente da ocupação prévia de cargos eletivos.
\end{abstract}

PALAVRAS-CHAVE: eleições; posição social; seleção social; titulação escolar; política e carisma de função; processos eleitorais e investimentos financeiros.

\section{INTRODUÇÃO}

O problema geral abordado é constituído pelas relações entre recursos de posição social, investimentos financeiros em campanhas e resultados em disputas eleitorais de diferentes níveis. Foram incluídos os candidatos às eleições municipais de 2004 e eleições gerais de 2006. No que tange aos recursos de posição social foram examinadas particularmente as associações com a condição profissional e com a titulação escolar. Como os cargos eletivos ocupados quando do registro da candidatura, em geral, são classificados como "ocupação profissional”, é possível examinar seus efeitos nas disputas e resultados eleitorais. Conforme a hipótese geral perseguida, por um lado, ocorre um processo de concentração nas categorias ocupacionais que representam posição social mais alta e mais fortemente associada à titulação escolar mais valorizada, na medida em que o cargo em disputa é hierarquicamente mais elevado. Além disso, nas disputas para cada cargo tomado separadamente, os efeitos desses recursos estão presentes nas chances de sucesso eleitoral. Por outro lado, além dos recursos associados à ocupação e ao grau de escolarização, na medida em que o cargo em disputa é mais elevado e as chances de sucesso são mais altas, também cresce o peso do "carisma de função" decorrente da ocupação prévia de cargos eletivos. Para os cargos hierarquicamente mais elevados e os candidatos com mais sucesso eleitoral essa ocupação prévia de cargos passa a ser o principal recurso eleitoral.

Apesar de tratar-se de um problema específico, ou seja, as relações entre candidaturas a cargos eletivos em diferentes níveis e determinados recursos sociais está inscrito em uma série de questões e confrontos mais gerais. Um dos principais desses confrontos está centrado nos problemas relativos às relações entre a profissão ou, em termos mais gerais, a condição social de origem e a entrada e carreira ou a "profissão" política. Algumas das principais posições teóricas e esquemas analíticos relativamente a esse tipo de questão remontam às formulações de Max Weber, para quem, nas relações entre posição e inserção social de origem e entrada e carreira política, os principais condicionantes podem ser sintetizados em dois: a disponibilidade de recursos para a própria manutenção econômica e o grau de afinidade entre 
as atividades profissionais de origem e da atuação política (WEBER, 1982, p. 107-139; 1984, p. 233, 1106-1117). Evidentemente, trata-se de relações que dependem de condições históricas concretas e o problema dos recursos para manutenção modifica-se com a progressiva profissionalização e remuneração pública das atividades de representação política. De modo semelhante, as relações entre as predisposições e habilidades nas atividades profissionais de origem e aquelas da política (nas condições históricas consideradas por Max Weber algumas profissões apresentariam determinadas vantagens em detrimento de outras) atualmente são completamente distintas. No que tange especificamente ao recrutamento de políticos no Brasil do período recente, por exemplo, foi possível demonstrar que nessas relações entre condições e atividades profissionais de origem e a entrada e carreira política há um peso decisivo das atividades anteriores na organização e representação de interesses (CORADINI, 2007). Isso, no entanto, não pode ser generalizado para qualquer outra configuração política. Como esse tipo de relação depende de condições concretas específicas e as Ciências Sociais não dispõem de respostas unívocas e definitivas, não é surpreendente que mesmo trabalhos com posições teóricas próximas, como aqueles editados por Offerlé (1999), podem polarizar-se quanto a esse tipo de questão, atribuindo importância diferente à análise sóciográfica, como é o caso, por exemplo, das respectivas posições de Dogan (1999) e Sawicki (1999).

Como parece evidente, a principal questão de fundo nesses confrontos decorre do grau concebido ou pressuposto de autonomia do espaço político frente às demais esferas de atividades sociais. Mais especificamente, entra em pauta a formação e autonomização da "profisssão política" frente às demais "profissões" ou esferas de atividades. Esse tipo de discussão pode conter um alto grau de apriorismo e de deducionismo, particularmente quando entram em pauta as disputas entre posições teóricas mais "societalistas" em oposição a alguma corrente filiada ao chamado institucionalismo ${ }^{1}$. Por outro

1 Esse tipo de tema e de problemas conexos teve uma relativa expansão de publicações, inclusive sobre as condições brasileiras. No presente texto, no entanto, não são tomadas essas publicações diretamente como objeto lado, nos países centrais tem surgido uma série de trabalhos empíricos baseados em análises comparativas ou em outras abordagens empíricas que, simultaneamente, destaca determinadas tendências gerais no recrutamento de elites políticas, mas também põe em evidência a diversidade desses processos e de seus resultados. Para esse tipo de trabalho a análise das bases sociais (social background) não é excludente, mas complementar às demais dimensões, como a estrutura formal de ofertas de oportunidades políticas, as modalidades de organização e de ação das "empresas políticas" (partidos, mas também grupos de interesse), entre outras (ver particularmente BEST \& COTTA, 2000, p. 1-26).

Além disso, essa literatura tem destacado duas tendências gerais mais recentes no recrutamento de elites políticas, que estão diretamente vinculadas às preocupações do presente trabalho: a progressiva "profissionalização" da carreira política e o crescente peso do grau de escolarização no ingresso e na carreira política (ver Best e Cotta (idem) e, particularmente Best e Gaxie (2000); Borchert e Zeiss (2003)). Por outro lado, esses processos e seus resultados estão fortemente associados a cada situação e conjuntura nacional e suas condições sociais e políticas específicas. No que tange especificamente aos padrões de recrutamento relativamente aos níveis dos cargos, em termos comparativos, "não há necessariamente uma ordem das coisas que privilegiam o nacional sobre o nível do estado ou regional e do último sobre o local. Em muitos países alguém passar de legislador nacional para o Executivo do Estado ou então da legislatura regional para Prefeito de cidade grande é considerado uma ascensão, enquanto em outros tais deslocamentos poderiam ser vistos como uma degradação inconcebível" (BORCHERT \& ZEISS, 2003, p. 16-17). Em todo caso, sobre "os fenômenos concernentes aos padrões de carreiras nós ainda conhecemos muito pouco" (ibidem).

de confronto. Isso porque, apesar de mais ou menos próximas em termos temáticos, suas respectivas questões analíticas e recortes são outros. Por outro lado, boa parte dessas publicações está mais preocupada com problemas prescritivos, na linha do "bom governo", quando não algo como o "bom partido" e até as "boas elites", o que as exclui de qualquer consideração analítica. 
Mas, como os resultados da análise expostos nos próximos itens parecem evidenciar, no caso em pauta, ocorrem determinados padrões e tendências bem definidos nas relações entre as candidaturas e suas chances de sucesso e as ocupações profissionais de origem e a titulação escolar. Evidentemente, trata-se de associações estatísticas e o perigo é tomá-las como determinações. Outro perigo é tomar essas relações entre formação escolar e condição profissional com candidaturas e sucesso eleitoral como decorrentes do conteúdo intrínseco dessa formação escolar. Como os resultados expostos adiante indicam, tanto entre candidatos bem como os mal sucedidos, não há alguma ligação significativa com o conteúdo da formação, mas com a importância social do título escolar, como ocorre, por exemplo, com os advogados e os médicos. Portanto, a principal questão não está nas relações entre o conteúdo intrínseco de determinadas atividades profissionais e formação escolar com atividades políticas, mas entre posição e legitimidade social e suas possibilidades de conversão em legitimidade política, como indicado na análise de Gaxie (1980).

Mas, se as possibilidades de candidatura e mais ainda, as chances eleitorais estão diretamente associadas com recursos de posição social, como a condição ocupacional declarada e a titulação escolar e o carisma de função obtido pela ocupação prévia de cargos públicos, esses mesmos recursos estão fortemente relacionados com o montante dos investimentos nas campanhas e com os resultados eleitorais. Como é apresentado adiante, há uma forte associação entre a distribuição por categoria ocupacional e por titulação escolar, além da ocupação prévia de cargos públicos, com o montante das despesas declaradas na eleição e a respectiva votação, para cada cargo em disputa. Para essas relações das candidaturas e do sucesso eleitoral com os recursos financeiros declarados investidos na campanha, a hipótese de trabalho principal é aquela formulada por Ihl (1999) para o caso norte-americano. Conforme o mesmo, a “campanha eleitoral não está aberta para os candidatos que querem e sabem se apresentar. Ela está aberta em primeiro lugar aos candidatos que podem financiá-las. Os agentes das campanhas eleitorais evidentemente podem ser alocados pelos partidos" (idem, p. 334), mas, nos Estados Unidos, cada vez mais, a regra é o autofinanciamento ${ }^{2}$.

\section{OCUPAÇÃO DE ORIGEM, TITULAÇÃO ESCOLAR E CARGO EM DISPUTA}

O grau de associação entre as categorias ocupacionais de origem, no caso, em 15 agrupamentos $^{3}$, com o cargo em disputa e com as chances de sucesso eleitoral é relativamente forte. Em termos gerais, tomando o conjunto dos candidatos não eleitos de todos os cargos em disputa, há uma forte associação entre os comerciantes e os trabalhadores, funcionários e trabalhadores do comércio, serviços e indústria em geral e os outros proprietários - agricultores, pecuaristas, etc., com os candidatos a Vereador. No extremo oposto destacam-se, em primeiro lugar, os candidatos a Governador e a Senador, com associação mais direta com os médicos.

2 Os dados relativos aos gastos na campanha eleitoral utilizados consistem em informações oficialmente declaradas e, sendo assim, é evidente que podem não equivaler aos gastos efetivos. Em síntese, trata-se de dados aproximativos, que devem ser considerados como parciais e com muita cautela. Isso, no entanto, não exclui as possibilidades de sua utilização como indicação, com a vantagem, inclusive, de serem sistemáticos. Os problemas da qualidade dos dados incluem outros indicadores, particularmente as classificações profissionais ou ocupacionais, inclusive porque consistem em dados oficiais da Justiça Eleitoral, cuja coleta, classificação e divulgação obedece a interesses diversos Todos os dados utilizados são provenientes das eleições municipais de 2004 e das eleições gerais de 2006. Esses dados foram obtidos no Tribunal Superior Eleitoral (TSE) em $1^{\circ} \mathrm{de}$ abril de 2009, não tendo sido consideradas as eventuais modificações posteriores.

3 As categorias ou agrupamentos são os que seguem: empresário; comerciante; administrador; diretor de empresas; outros proprietários (agricultores, pecuarista etc.); funcionários públicos em geral (todos os níveis, inclusive militares e aposentados); ocupante de cargo público eletivo (todos os níveis); médico; engenheiro; advogado; outros profissionais com titulação universitária (exceto médicos, advogados e engenheiros); professor de ensino superior; professor de ensino fundamental e médio; funcionários, técnicos e trabalhadores do comércio, serviços e indústria em geral e, por fim, os classificados como "outros" ou em "ocupações mal definidas". A categoria dos eleitos restringe-se aos considerados como tais pela Justiça Eleitoral, mas a dos não eleitos inclui todos os demais, tais como não eleitos propriamente ditos, desistências, suplência etc. 
Ainda nesse polo, em uma situação menos extrema, destacam-se os candidatos a Deputado Federal, a Prefeito e a Deputado Estadual em associação mais direta com os engenheiros, advogados, ocupantes de cargos públicos eletivos (todos os níveis), professor de ensino superior, empresários e diretores de empresa. Ainda nesse nível geral, ao tomar apenas os candidatos eleitos, algumas posições básicas continuam as mesmas, mas também ocorrem alterações significativas. A principal dessas alterações é a aproximação dos candidatos a Deputado Federal e a Deputado Estadual dos candidatos a Governador e a Senador, todos muito fortemente associados particularmente com os médicos e engenheiros. Os empresários, diretores de empresas, advogados, professores de ensino superior, ocupantes de cargos públicos eletivos (todos os níveis) e os outros profissionais com titulação universitária - além de médicos, advogados e engenheiros continuam a ocupar uma posição menos extrema nesse polo, em associação mais direta com os candidatos a Prefeito. No polo contrário continuam a posicionar-se os candidatos a Vereador, em associação mais direta com os comerciantes, outros proprietários - agricultores, pecuaristas etc., funcionários públicos em geral e funcionários, técnicos e trabalhadores do comércio, serviços e indústria em geral.

Em termos numéricos, apenas para mencionar alguns casos exemplares, no polo correspondente aos cargos hierarquicamente mais baixos, particularmente o de Vereador, essas associações com agrupamentos ocupacionais não chegam a apresentar diferenças mais significativas. Por exemplo, entre os candidatos a Vereador não eleitos a proporção de comerciantes $(11,4 \%$ contra $11,3 \%$ do conjunto do universo) e de funcionários, técnicos e trabalhadores do comércio, serviços e indústria em geral $(23,2 \%$ contra $22,3 \%$ do conjunto do universo) nem chega a apresentar muitas diferenças relativamente ao conjunto do universo. Com os candidatos a Vereador eleitos ocorre algo semelhante. Por outro lado, no que tange ao polo contrário, dos cargos mais altos, as diferenças são muito significativas. Por exemplo, os candidatos a Senador não eleitos têm mais de quatro vezes $(4,3 \%$ contra $1 \%$ do conjunto do universo) mais médicos que o conjunto do universo, mais que essa proporção $(4,9 \%$ contra $0,5 \%)$ de professores de ensino superior, cinco vezes mais $(9,8 \%$ contra $2 \%)$ de ocupantes de cargos públicos eletivos (todos os níveis), mais de oito vezes mais $(16,5 \%$ contra $2 \%$ ) de advogados e algo semelhante ocorre com uma série de categorias social e escolarmente em melhores condições. Ao tomar os candidatos a Senador eleitos essas tendências aprofundam-se, com quase a terça parte $(30,8 \%)$ contra menos da décima parte $(8,8 \%)$ do conjunto do universo composta de ocupantes de cargos públicos eletivos (todos os níveis). Para os candidatos a Governador, a Deputado Federal e a Deputado Estadual ocorre algo semelhante, sendo que entre os candidatos eleitos a Governador $(58,8 \%)$ e a Deputado Federal $(47,1 \%)$ cerca da metade é ocupante de cargo público eletivo (todos os níveis) e o restante é classificado em categorias com maior grau de associação com titulação universitária valorizada, como médicos, advogados, engenheiros, ou que indicam para posição socialmente mais alta, como os empresários.

No que tange às relações entre a titulação escolar, os cargos em disputa e as chances de sucesso, por tratar-se de categorias com princípio de hierarquização mais formalizado, os resultados mostram tendências mais claras e diretas. Além da intensidade dessas relações, há também uma forte equivalência entre o grau de titulação escolar e o nível do cargo em disputa, além das chances de sucesso eleitoral.

Ao tomar o conjunto dos candidatos não eleitos relativamente ao grau de escolarização e aos cargos em disputa fica evidente a forte associação dos candidatos, por ordem, a Governador, Senador, Deputado Federal, Deputado Estadual e, em menor grau, a Prefeito, com o curso superior completo. Em uma situação intermediária, os candidatos a Prefeito estão também fortemente associados aos que têm curso superior incompleto. No extremo oposto situam-se os candidatos a Vereador, mais diretamente associados com os que apenas lêem e escrevem, com o curso fundamental incompleto e, em menor grau, também com o curso superior incompleto.

Em termos numéricos, para mencionar apenas alguns exemplos, entre os candidatos a Vereador não eleitos há $5,18 \%$ (contra $4,86 \%$ do conjunto do universo) que apenas lêem e escrevem e $17,77 \%$ (contra $16,02 \%$ do conjunto do universo) com o curso superior incompleto. No polo oposto os candidatos a Senador não eleitos têm uma quantidade muito pequena $(0,6 \%)$ dos que apenas 
lêem e escrevem e bem mais da metade $(66,87 \%)$ com curso superior completo e a situação dos candidatos não eleitos a Governador, a Deputado Federal e a Deputado Estadual é semelhante.

Ao tomar os candidatos eleitos, essas relações entre titulação escolar e cargo em disputa ficam bem mais intensas. Nesse caso também, no extremo do polo da maior titulação escolar e mais especificamente, correspondendo aos com curso superior completo, destacam-se em um bloco à parte os candidatos a Senador, Governador, Deputado Federal e Deputado Estadual. Os candidatos a Prefeito ocupam uma posição intermediária, mas ainda fortemente associados ao curso superior completo, embora também ao curso superior incompleto. No extremo oposto, nesse caso também se posicionam somente os candidatos a Vereador, correspondendo mais diretamente aos que apenas lêem e escrevem, com o curso fundamental completo ou incompleto e com o ensino médio completo ou incompleto.

Porém, em termos numéricos, para esses candidatos eleitos as associações são bem mais altas. Embora para os candidatos a Vereador a quantidade dos que apenas lêem e escrevem seja significativa tanto para os não eleitos como para os eleitos $(4,55 \%$ dos candidatos a Vereador eleitos contra $4,08 \%$ do conjunto do universo) para os candidatos a Senador, a Deputado Federal e a Governador não há ocorrência dessa categoria. Algo semelhante ocorre com os graus escolares imediatamente acima, com proporções significativas entre os candidatos a Vereador e até mesmo a Prefeito e inexistente para os candidatos aos cargos mais altos. No extremo oposto, correspondendo aos com curso superior completo, há uma proporção de menos da quinta parte $(16,19 \%)$ entre os candidatos a Vereador eleitos e de quase três quartos $(73,08 \%)$ para os candidatos a Senador eleitos, ocorrendo algo semelhante entre os candidatos a Governador (70,59\%), Deputado Federal (81,42\%) e Deputado Estadual (67,32\%), com os candidatos a Prefeito eleitos em uma situação intermediária $(40,95 \%)^{4}$. Ou seja, há uma relação direta entre o grau de escolarização e o nível do cargo em disputa.

Passando para a dimensão mais política e, mais

\footnotetext{
4 Foi também incluída na análise a distribuição por idade e por sexo, mas como os resultados não chegam a ser muito significativos, não são expostos.
}

especificamente, para a distribuição conforme a filiação partidária, como seria de esperar, há um aumento da concentração em uma quantidade menor de partidos na medida em que o cargo em disputa é mais elevado e conforme o sucesso eleitoral. Para os cargos mais baixos, como aquele de Vereador e, particularmente, para os candidatos a Vereador não eleitos, apesar de uma relativa concentração entre os partidos eleitoralmente mais fortes, a distribuição abrange quase todo o conjunto de 29 partidos em disputa. Para os candidatos a Vereador eleitos esse padrão de distribuição modifica-se completamente, sendo que a quase totalidade concentra-se em alguns poucos partidos. Por sua vez, os candidatos aos cargos mais altos essa tendência aprofunda-se.

Em síntese, o processo de concentração na medida em que se eleva na hierarquia dos cargos disputados e do sucesso eleitoral em cada cargo segue determinadas tendências comuns, que abrangem tanto os partidos como as ocupações profissionais. Há uma tendência de concentração em partidos eleitoralmente mais fortes. Esse processo de concentração, por um lado, evidentemente, está vinculado aos próprios processos de disputas eleitorais, em que entram em pauta os recursos conversíveis em votação, inclusive aqueles de cunho organizacional ou institucional. Esse aspecto nem cabe ser detalhado, visto que é fortemente redundante com os próprios processos eleitorais em sua apresentação oficial e pública. Por outro lado, essa concentração das candidaturas e dos resultados eleitorais em determinados partidos está fortemente relacionada com suas bases sociais. Para a demonstração disso, entre os indicadores disponíveis, podem ser tomadas a condição ocupacional e a titulação escolar.

Além do fato de que há um grau de associação forte entre filiação partidária, ocupação profissional e titulação escolar, como é indicado adiante, isso também ocorre quanto aos investimentos nas campanhas eleitorais. Apesar de que apenas com os indicadores disponíveis não seja possível caracterizar de modo mais detalhado as relações entre a filiação partidária com determinado setor ou segmento das "elites" para cada partido (como apresentado por Gaxie (1980)), os resultados do exame dos dados disponíveis indicam grau relativamente alto de associação com as categorias ocupacionais de origem. Porém, no que tange às relações entre a 
filiação partidária e categorias ocupacionais, não apenas a direção, mas também a intensidade das associações varia para cada partido, o que não exclui algumas semelhanças ou justaposições entre alguns deles. Tomando apenas os candidatos não eleitos, fica muito claro um primeiro polo, grosso modo, correspondendo à esquerda no espectro político, no qual se situam particularmente os classificados como outros proprietários agricultores, pecuaristas etc. em associação muito direta com o Partido dos Trabalhadores (PT), o Partido Trabalhista do Brasil (PTdoB) e o Partido Comunista do Brasil (PCdoB). Evidentemente, trata-se de um agrupamento de "proprietários" muito particular e tudo indica que há uma forte participação de "pequenos proprietários", que inclusive na legislação sindical são enquadrados como "trabalhadores", como é o caso de boa parte dos agricultores. Outro polo corresponde mais diretamente com os diretores de empresas, comerciantes, empresários, médicos, advogados, administradores, engenheiros, entre outras categorias, em associação mais direta com partidos como o PRONA, PRP, PRTB, PPS, PFL, PSDC, PP, PMDB 5 , entre outros. Ao tomar apenas os candidatos eleitos essa estrutura não sofre alterações mais significativas.

Para tomar alguns casos exemplares em termos numéricos: a proporção de professores de ensino superior entre os candidatos do PT não eleitos é de quase o dobro ( $0,86 \%$ contra $0,48 \%)$ do conjunto do universo e ao tomar apenas os candidatos eleitos essa proporção eleva-se em mais de três vezes $(1,39 \%$ contra $0,44 \%$ do conjunto do universo). De modo semelhante, a proporção de outros proprietários - agricultores, pecuaristas etc. no PT é de um terço a mais $(18,76 \%$ contra $13,85 \%$ do conjunto do universo) entre os candidatos não eleitos. Quanto aos professores de ensino fundamental e médio, sua proporção entre os candidatos não eleitos do Partido Socialista dos Trabalhadores Unificado (PSTU) é de mais de três vezes à do conjunto do universo (20,6\% contra 6,22\%). Entre os candidatos eleitos do PSTU essa proporção é de quase o dobro

\footnotetext{
5 Respectivamente: Partido da Reedificação da Ordem Nacional, Partido Republicano Progressista, Partido Renovador Trabalhista Brasileiro, Partido Popular Socialista, Partido da Frente Liberal, Partido Progressista e Partido do Movimento Democrático Brasileiro.
}

(13,39\% contra $7,02 \%)$. No extremo oposto, ao tomar apenas os candidatos eleitos, a proporção de empresários no Partido Social Democrata Cristão (PSDC) é de quase o dobro do conjunto do universo $(4,93 \%$ contra 2,84\%). Algo semelhante ocorre entre os comerciantes e o Partido Trabalhista Nacional (PTN) (17,37\% contra $12,19 \%$ do conjunto do universo) entre os candidatos eleitos e os advogados e o Partido da Mobilização Nacional (PMN) $(4,06 \%$ contra $2,42 \%)$ e os médicos e o Partido da Social Democracia Brasileira (PSDB) (2,69\% contra $2,14 \%$ do conjunto do universo).

Mas, se a ocupação e a titulação escolar estão diretamente associadas ao tipo de cargo e com o sucesso ou fracasso eleitoral, isso ocorre também com o "empreendimento eleitoral", ou seja, a candidatura como investimento financeiro e retorno eleitoral. Tanto a quantidade de votos (para um mesmo cargo em disputa) como o montante de gastos eleitorais declarados estão diretamente relacionados com a ocupação e com a titulação escolar. O grau de associação dessa relação, no entanto, é completamente variável conforme o sucesso ou fracasso (eleito ou não eleito) e o cargo em disputa. Isso indica que o grau de homogeneidade dos candidatos aumenta na medida em que são tomados os melhor sucedidos em termos eleitorais e, também, os cargos em disputa mais elevados.

Essas tendências vão ao encontro do constatado para outras configurações nacionais. Ou seja, por um lado, a expansão da politização através de processos eleitorais tem como interesse principal o empresário político (LACROIX, 1985, p. 537). Por outro lado, como destacado por Best e Gaxie (2000, p. 117-125), o processo de maior "profissionalização" das atividades de representação política é paralelo à crescente homogeneização dos ocupantes dos cargos mais altos. Simultaneamente, aumenta a distância entre os representantes e os representados, conjuntamente com o aumento da seletividade social dos primeiros. Esse aumento da seletividade tem como principal implicação o aumento da super-representação de determinadas esferas e posições sociais mais próximas do espaço político, que se manifesta, inclusive, nas condições ocupacionais e educacionais dos eleitos para os principais cargos. Mas, como já mencionado, isso está diretamente associado com o montante de 
investimentos nas campanhas e com os resultados eleitorais.

Para os candidatos não eleitos sem distinção de cargo em disputa, o grau de associação entre o montante dos gastos na eleição e a quantidade de votos é quase nula ${ }^{6}$ (R 0,001 e R Quadrado de 3,831 na regressão linear). Porém, mesmo tomando em conjunto, sem discriminação por cargo, para os candidatos eleitos a associação entre o montante de gastos na campanha e a quantidade de votos é muito intensa (R 0,654 e R Quadrado 0,428). Ao tomar os candidatos não eleitos por cargo em disputa o grau dessa associação mantém-se, em geral, bem fraco. Isso abrange, particularmente, os candidatos não eleitos a Vereador (R 0,001 e R Quadrado 1,546), Prefeito (R 0,014 e R Quadrado 0,000), Deputado Estadual (R 0,008 e R Quadrado 6,869) e Deputado Federal (R 0,036 e R Quadrado 0,001). Para os candidatos a Governador (R 0,475 e R Quadrado 0,225) e a Senador (R 0,669 e R Quadrado 0,447) essa associação é muito significativa inclusive para os não eleitos. Ou seja, fica evidente que a maior inserção no universo e na carreira política equivale a um processo de homogeneização que inclui a média dos gastos e da votação.

Para os candidatos eleitos, o grau de associação entre o montante dos gastos na campanha e a votação é, em geral, muito intenso, mesmo ao tomar em conjunto, sem discriminação de cargo em disputa (0,654 e R Quadrado 0,428). Porém, as variações conforme o cargo em disputa são muito fortes. Essa intensidade da associação inclui os candidatos a Vereador (R 0,504 e R Quadrado $0,254)$, sendo um pouco menor para os candidatos a Prefeito (R 0,351 e R Quadrado 0,123) e mais forte para os a Deputado Estadual (R 0,507 e $\mathrm{R}$ Quadrado 0,257). A principal exceção são os candidatos a Deputado Federal, que mesmo para os eleitos o grau de associação é baixíssimo (R 0,097 e R Quadrado 0,009). Talvez, a principal razão disso esteja na forte heterogeneidade dos candidatos, por incluir condições regionais muito diversas. Por fim, para os candidatos eleitos a

\footnotetext{
6 Evidentemente, há diversas formas de demonstração disso e, no caso, foram usados, particularmente, testes de regressão linear. Para o exame das relações entre o montante dos gastos e a votação obtida com as categorias ocupacionais e a titulação escolar foram usados principalmente testes de comparação de médias. Para mais detalhes, ver o anexo estatístico.
}

Governador (R 0,868 e R Quadrado 0,754) e a Senador eleitos (R 0,519 e R Quadrado 0,270) esse grau de associação entre o montante dos gastos na campanha e a quantidade de votos é a mais alta.

Mas, se há um forte grau de associação entre a média do montante dos gastos na campanha e a quantidade de votos, tanto a quantidade de investimentos financeiros declarados como sua conversão em votação estão diretamente relacionados com a categoria ocupacional e a titulação escolar, além de outros recursos. Sendo assim, se, como sustentado por Ihl (1999, p. 334), o processo de profissionalização da carreira política tem requerimentos econômicos e também está associado à posição social, que se expressa, inclusive, na condição ocupacional e na titulação escolar. Além dessa condição ocupacional, é muito importante a ocupação prévia de cargo público, o que pode estar associado a determinados processos de profissionalização da carreira política, que constitui uma das tendências mais gerais no período recente (BEST \& COTTA, 2000; BORCHERT \& ZEISS, 2003). No entanto, ao que tudo indica, no caso em pauta é decisivo o carisma de função, o que é reforçado pelo spoil system formado pelas estreitas relações entre a entrada na carreira política por meio de cargos de "confiança" e da competição eleitoral. Um bom indicador indireto disso (já que, lamentavelmente, os dados disponíveis não discriminam os ocupantes de cargos públicos de "confiança") é que apesar da forte associação dos ocupantes de cargos públicos eletivos com o maior sucesso eleitoral, o mesmo não ocorre com os funcionários públicos em geral.

Seja como for, ao relacionar as categorias ou agrupamentos ocupacionais (no caso, em 15 categorias) com as médias de gastos e de votação, resultam determinadas tendências com padrões bem definidos, apesar da relativamente forte dispersão quanto aos gastos e à votação ${ }^{7}$. Esses padrões são muito característicos para cada cargo

7 Como parece evidente, é possível demonstrar essas relações entre recursos financeiros declarados, resultados eleitorais, categorias ocupacionais e titulação escolar a partir de diferentes possibilidades técnicas. Como se pode constatar no anexo, além de tabelas cruzadas para demonstrar as relações entre as categorias ocupacionais e da titulação escolar com os cargos em disputa e com a 
em disputa tomado em separado, mas, simultaneamente, ficam evidentes determinadas tendências gerais que dependem do nível do cargo em disputa.

Ao tomar, inicialmente, os candidatos em disputa pelo cargo de nível mais baixo, o de Vereador, relativamente às categorias ocupacionais, sem separação entre eleitos e não eleitos (visto que é a votação que está em pauta), a primeira constatação geral é a de que o rank dos gastos na campanha e da votação são quase idênticos. Essa tendência geral da forte homologia entre essas duas ordens acompanha todos os cargos em disputa, com suas variações específicas para cada caso, sendo que as respectivas posições das categorias ocupacionais são relativamente próprias conforme o nível do cargo.

Em termos mais específicos no que tange aos candidatos a Vereador, a posição extrema inferior quanto aos gastos é ocupada pelos outros proprietários - agricultores, pecuaristas etc. (média de gastos por voto de R\$10 190 e erro padrão de R\$ 129,14), seguidos pelos funcionários, técnicos e trabalhadores do comércio, serviços e indústria em geral e, sucessivamente, por uma série de categorias crescentemente com melhor posição social na medida em que se aproxima do polo oposto. O extremo desse polo oposto, no que tange aos gastos é ocupado pelos médicos (média de R\$ 63 920,27 e R \$586,71 de erro padrão), seguidos pelos engenheiros e assim sucessivamente. Ao confrontar esse rank relativo

filiação partidária, foram utilizados testes de regressão linear para analisar as relações entre o montante dos gastos e a quantidade da votação. Para demonstrar as relações entre as médias de gastos e da votação com as categorias ocupacionais e a titulação escolar foram utilizados testes de comparação de médias. Evidentemente, não caberia uma exposição do conjunto dos resultados desses testes. No entanto, tendo em vista a indicação não apenas do grau de associação, mas também de dispersão, no anexo estatístico foi incluído o erro padrão (que tem a vantagem comparativamente ao desvio padrão de contemplar as variações quanto ao tamanho dos diferentes universos). No que tange às relações das categorias ocupacionais e a titulação escolar com o montante dos gastos e a quantidade da votação também foi utilizada a técnica de transformação da cada categoria em uma variável dummy para sua utilização em testes de regressão, cujos resultados não são expostos, inclusive, pelo alto grau de redundância com os demais. à média dos gastos com aquele da quantidade de votos, a principal e quase única alteração significativa é a passagem dos ocupantes de cargos públicos eletivos (todos os níveis) da posição intermediária quanto aos gastos para o extremo superior no rank da votação. Ou seja, trata-se da categoria cujos investimentos eleitorais resultam em maior "retorno", o que, evidentemente, está associado à ocupação prévia de cargos. Disso resulta outra tendência geral que, apesar das peculiaridades de cada cargo em disputa, abrange o conjunto dos candidatos. Tratase da posição invertida em outro rank, que é formado pelo resultado da divisão do montante dos gastos pela quantidade de votos. Os ocupantes de cargos públicos eletivos (todos os níveis), invariavelmente, ocupam a posição extrema inferior, ou seja, aquela de menor "custo unitário" do voto. Ou seja, para os que já ocupam cargos públicos eletivos o custo do voto é sistematicamente menor. No caso específico dos candidatos a Vereador (média de $\mathrm{R} \$ 63,39$ por voto, com erro padrão de R $\$ 6,48)$, os ocupantes de cargos públicos eletivos (todos os níveis) são seguidos pelos outros proprietários - agricultores, pecuaristas etc., pelos médicos e sucessivamente pelas demais categorias, com os classificados como outros ou em ocupações mal definidas na posição extrema superior quanto ao custo do voto, ou seja, com custo unitário mais alto (média de $\mathrm{R} \$ 377,85$ por voto, com erro padrão de R\$ $25,49)$.

Para os candidatos a Prefeito as tendências gerais mantêm-se, mas também ocorrem algumas mudanças significativas. Uma das principais dessas mudanças no que tange à média dos gastos é a posição extrema superior dos ocupantes de cargos públicos eletivos (todos os níveis) - média de $\mathrm{R} \$ 499$ 612,23 e erro padrão de $\mathrm{R} \$ 36$ 834,24. O mesmo ocorre com a votação (média de 30535,56 votos e erro padrão de 6382,78 ). No topo da média do montante dos gastos, um primeiro agrupamento é formado, pelos ocupantes de cargos públicos eletivos (todos os níveis), professores de ensino superior, engenheiros, advogados e empresários, ou seja, todas categorias com posição social mais alta e titulação escolar mais valorizada, seguidos por uma série de agrupamentos intermediários. No extremo oposto situam-se os outros proprietários - agricultores, pecuaristas etc. (média de R\$ 139608,04 e erro padrão de R\$ 4 494,68), seguidos pelos funcionários, 
técnicos e trabalhadores do comércio, serviços e indústria em geral, professores de ensino fundamental e médio e os classificados como outros ou em ocupações mal definidas, ou seja, em geral, categorias indicando para posições socialmente mais baixas. Esse é praticamente o mesmo rank da média de votos. Conseqüentemente, o rank do custo unitário do voto é aproximadamente o inverso daquele da média dos gastos e da votação. No extremo inferior, do menor custo, destacam-se os ocupantes de cargos públicos eletivos (todos os níveis) - média de $\mathrm{R} \$ 84,54$ por voto, com erro padrão de R $\$ 10,83$, seguidos pelos professores de ensino superior, médicos, administradores e assim sucessivamente. No extremo oposto se destacam os advogados (média de R $\$ 274,28$ e erro padrão de R \$49,94), portanto, fugindo da tendência geral. Porém, logo a seguir se situam os classificados como outros ou em ocupações mal definidas, funcionários, técnicos e trabalhadores do comércio, serviços e indústria em geral e os professores de ensino fundamental e médio, dentre outras categorias, como tende a ocorrer também nos demais casos.

Para os candidatos a Deputado Estadual os resultados são muito semelhantes, com algumas poucas alterações significativas. Nesse caso também o rank formado pela média dos gastos é quase idêntico àquele da votação. Uma das principais alterações no que tange aos gastos é a ocupação da posição extrema pelos diretores de empresa (média de um R \$ 1 milhão e erro padrão de $R \$ 172$ 396,20), seguidos pelos empresários e a exemplo dos demais cargos em disputa, seguidos de perto pelos ocupantes de cargos públicos eletivos (todos os níveis). No extremo oposto, destacam-se os professores de ensino fundamental e médio (média de R $\$ 516$ 666,67 e erro padrão de R\$ 21 199,23), comerciantes, e funcionários públicos em geral (todos os níveis, inclusive militares e aposentados). Outro conjunto no polo inferior é formado pelos classificados como "outros" ou em "ocupações mal definidas", os funcionários, técnicos e trabalhadores do comércio, serviços e indústria em geral e os outros proprietários - agricultores, pecuaristas etc., ou seja, aquelas categorias ocupacionais que indicam para posição social menos elevada. Como mencionado, o rank da votação é muito semelhante, com algumas pequenas alterações. No extremo superior da votação situam-se os ocupantes de cargos públicos eletivos (todos os níveis) - média de 23411,11 votos e erro padrão de 717,09. A seguir situam-se os médicos, engenheiros, advogados, diretores de empresa, ou seja, aquelas categorias que geralmente situamse nesse polo superior. No extremo oposto, como na maior parte dos casos, destacam-se os funcionários, técnicos e trabalhadores do comércio, serviços e indústria em geral (média de 1899,77 votos e erro padrão de 161,08), seguidos pelos funcionários públicos em geral (inclusive militares e aposentados), comerciantes e classificados como outros ou em ocupações mal definidas. No extremo inferior do rank do custo destacam-se, como em geral ocorre também nos demais casos, os ocupantes de cargos públicos eletivos (todos os níveis) - média de $\mathrm{R} \$ 385,82$ e erro padrão de 100,02 , médicos, engenheiros, administradores, diretores de empresa e professores de ensino superior. No extremo oposto situam-se os funcionários, técnicos e trabalhadores do comércio, serviços e indústria em geral (média de R \$3 322,25 e erro padrão de R\$ 289,24), os classificados como "outros" ou em "ocupações mal definidas", professores de ensino fundamental e médio e os outros proprietários - agricultores, pecuaristas etc.

Para os candidatos a Deputado Federal os resultados também são muito semelhantes e, no que tange à média dos gastos, uma pequena diferença comparativamente aos candidatos a Deputado Estadual é a posição no extremo do polo superior dos diretores de empresa (média de R\$ 1633333,00 e erro padrão de $\mathrm{R} \$ 357$ 460,20), seguidos pelos engenheiros. Porém, como na maior parte dos casos, embora na terceira posição, no extremo desse polo também se destacam os ocupantes de cargos públicos eletivos (todos os níveis), seguidos pelos médicos, administradores, empresários e advogados, entre outras categorias. No extremo oposto, também como geralmente ocorre, destacam-se os funcionários, técnicos e trabalhadores do comércio, serviços e indústria em geral (média de R $\$ 871$ 028,72 e erro padrão de R $\$ 31$ 864,75), seguidos pelas demais categorias que em geral posicionam-se no extremo desse polo. Esse rank é muito semelhante àquele da votação, no qual o extremo do polo superior destacam-se os ocupantes de cargos públicos eletivos (todos os níveis) - média de R\$ 64971,77 e erro padrão de $\mathrm{R} \$ 2$ 955,23, seguidos de perto pelos engenheiros, 
médicos, advogados e demais categorias que geralmente posicionam-se nesse polo. $\mathrm{O}$ extremo do polo contrário é ocupado pelos comerciantes (55 735,18 votos e erro padrão de 894,04), mas, como geralmente ocorre, seguidos de perto por categorias como os funcionários, técnicos e trabalhadores do comércio, serviço e indústria em geral e outras que também tendem a situar-se nesse polo. Conseqüentemente, no extremo inferior do custo unitário do voto situam-se os ocupantes de cargos públicos eletivos (todos os níveis) - média de R $\$ 159,03$ e erro padrão de $\mathrm{R} \$ 33,31$, seguidos pelos médicos e, no extremo oposto, as mesmas categorias que tendem a situar-se no mesmo, com os funcionários, técnicos e trabalhadores do comércio, serviços e indústria em geral no extremo.

Quanto aos candidatos a Governador, a principal diferença no que tange à média dos gastos é a posição dos outros proprietários agricultores, pecuaristas, etc. no extremo do polo superior (média de R \$ 10933 333,33 e erro padrão de R 4475 782). Porém, isso pode ser atribuído à ambivalência de categorias de classificação que compõem o agrupamento, tais como aquelas de agricultor e de pecuarista, além do universo dos candidatos a Governador ser muito restrito, com apenas três ocorrências nesse agrupamento. Para as demais categorias, os resultados são muito semelhantes aos demais casos, com os ocupantes de cargos públicos eletivos (todos os níveis) na posição imediatamente abaixo do extremo desse polo, seguidos pelos engenheiros, médicos, administradores e demais categorias que geralmente situam-se nesse polo. No extremo oposto também não ocorrem variações significativas, em que os funcionários públicos em geral (todos os níveis, inclusive militares e aposentados) ocupam a posição extrema (média de R $\$ 702$ 586,21 e erro padrão de R\$ 199 007,60), seguidos pelos funcionários, técnicos e trabalhadores do comércio, serviços e indústria em geral, e demais categorias que geralmente situam-se nesse polo. No que tange à média da votação, também ocorrem algumas pequenas diferenças, dentre as quais particularmente a posição extrema superior dos outros profissionais com titulação universitária - que não médicos, advogados, engenheiros e professores - média de 2069837 votos e erro padrão de 1199 470) e dos classificados como outros ou em ocupações mal definidas. Porém, como na maior parte dos casos, também se situam no extremo desse polo os ocupantes de cargos públicos eletivos (todos os níveis). No extremo oposto, também divergindo um tanto dos demais casos, destacam-se os administradores (média de 4791,67 e erro padrão de 2052,74 ), mas como tende a ocorrer, também se situando no extremo desse polo, categorias como os funcionários, técnicos e trabalhadores do comércio, serviços e indústria em geral, professores do ensino fundamental e médio, funcionários públicos em geral (todos os níveis, inclusive militares e aposentados), entre outras. Conseqüentemente, nesse caso, no que tange ao custo unitário do voto o extremo superior é ocupado pelos empresários (média de R \$889,70), seguidos pelos administradores e outras categorias. No extremo dos menores custos situam-se os outros proprietários - agricultores, pecuaristas etc. (média de R $\$ 20,99$ ), seguidos pelos professores de ensino superior e apenas na terceira posição, divergindo, portanto da maior parte dos casos, os ocupantes de cargos públicos eletivos (todos os níveis).

Por fim, no que tange às relações entre categorias ocupacionais e média de gastos e de resultados eleitorais, os candidatos a Senador também apresentam algumas pequenas diferenças, parte das quais podendo ser decorrentes do fato de tratar-se de um universo muito reduzido, particularmente para algumas categorias. Além disso, algumas são bastante ambivalentes. Nesse caso, o extremo superior da média dos gastos é ocupado pelos engenheiros (média de R $\$ 4800000$ e erro padrão de R $\$ 1593$ 738), seguidos pelos empresários e somente em terceiro lugar situam-se os ocupantes de cargos públicos eletivos (todos os níveis). No extremo inferior destacam-se os comerciantes (média de R\$ 438000 e erro padrão de $\mathrm{R} \$ 163535,90$ ), seguidos pelos professores de ensino superior, professores de ensino fundamental e médio e outras categorias que geralmente posicionam-se nesse polo. No que tange à média de votação, no extremo superior destacam-se os empresários (média de R \$ 1075415 votos e erro padrão de R\$ 619 221,40), mas a exemplo da maior parte dos casos, seguidos de perto pelos ocupantes de cargos públicos eletivos (todos os níveis). Conseqüentemente, no extremo do menor custo do voto destacam-se os engenheiros ( $\mathrm{R} \$$ 8,84 ), seguidos pelos ocupantes de cargos públicos eletivos (todos os níveis), professores de ensino superior, médicos e demais categorias 
que geralmente posicionam-se nesse polo. No extremo oposto destacam-se os administradores (média de R \$ 55,04), comerciantes, funcionários, técnicos e trabalhadores do comércio, serviços e indústria em geral, entre outras categorias. Em síntese, apesar de algumas alterações internas no rank da média dos gastos e da votação, para os candidatos a Governador e a Senador não chega a haver alterações mais significativas nas posições e nas tendências gerais.

Mas, se as relações entre as categorias ocupacionais e a média dos gastos em campanha e da votação, apesar de muito intensas, sofrem algumas variações conforme o cargo em disputa, no que tange à titulação escolar essas relações são mais diretas, além de mais intensas. Para quase todos os cargos em disputa, o rank da média dos gastos e da votação são idênticos e, além disso, homólogos à hierarquização da titulação escolar. Além da forte relação entre escolarização e participação eleitoral, essas relações tão diretas podem ser conseqüência do fato de que as classificações escolares são mais formais e explícitas, comparativamente àquelas das ocupações. Porém, se a hierarquização da titulação escolar está direta e intensamente relacionada com a média do montante dos investimentos eleitorais e com a votação obtida, não ocorre o mesmo com o tipo de título. Dito de outro modo, não é o conteúdo intrínseco da formação escolar, mas a legitimidade social do título como recurso eleitoral que entra em pauta. Uma das indicações mais fortes nesse sentido é o fato de que os títulos escolares mais fortemente associados com as maiores médias de gastos e de votação, particularmente os médicos, advogados e engenheiros, não têm nada em comum quanto ao conteúdo da formação. Em todo caso, os indicadores disponíveis não permitem que se avance muito mais na especificação desse tipo de relação.

Começando novamente pelos candidatos a Vereador, tomados em conjunto, a média do montante dos gastos forma exatamente o mesmo rank obtido pela votação, que corresponde à hierarquia da titulação escolar. Sendo assim, as variações restringem-se a pequenas diferenças internas. No que tange aos gastos, como em quase todos os demais cargos em disputa, no extremo inferior situam-se os que apenas lêem e escrevem (média de R $\$ 14$ 300,88 e erro padrão de R\$ 1 237,01), seguidos pelos com o curso fundamental incompleto, fundamental completo, médio completo, superior incompleto e demais níveis e no extremo oposto aqueles com curso superior completo (média de $\mathrm{R} \$ 46351,47$ e erro padrão de R $\$ 671,21)$. Como já mencionado, as posições relativamente à votação são as mesmas, com os que apenas lêem e escrevem no extremo inferior (média de 136,06 votos), passando sucessivamente pela titulação imediatamente acima até o extremo oposto, em que se situam os com curso superior completo (média de 570,36 votos). Isso não significa que essa homologia repita-se de maneira exata para a distribuição quanto ao custo unitário do voto. Nesse caso, no extremo superior situam-se os com curso superior incompleto (média de $\mathrm{R} \$ 379,64$ e erro padrão de $\mathrm{R} \$ 66,65)$, seguidos pelos com curso médio incompleto, entre outras categorias e no extremo inferior, os com curso superior completo (média de $\mathrm{R} \$ 270,01$ e erro padrão de $\mathrm{R} \$ 5,75)$.

Para os demais cargos em disputa os resultados são muito semelhantes e, portanto, não caberia sua apresentação detalhada. No caso dos candidatos a Prefeito também no extremo inferior da média dos gastos situam-se os que apenas lêem e escrevem (média de $\mathrm{R} \$ 113$ 863,16 e erro padrão de R\$ 9 380,65), seguidos sucessivamente pelos com titulação imediatamente acima até, no extremo oposto, aqueles com curso superior completo (média de R $\$ 308$ 422,35 e erro padrão de R $\$ 9$ $547,07)$. Essa é exatamente a mesma distribuição da votação média, com os que apenas lêem e escrevem no extremo inferior, as demais titulações sucessivamente e os com curso superior completo no topo. Isso, no entanto, não assegura o mesmo rank quanto ao custo unitário do voto, em que o extremo inferior é ocupado pelos com curso fundamental incompleto (média de R\$ 132,13 e erro padrão de R\$ 13,05), porém seguidos imediatamente pelos com curso superior completo. No extremo oposto superior situam-se os que apenas lêem e escrevem (média de R \$ 354,53) seguidos pelos com curso médio completo.

Para os candidatos a Deputado Estadual ocorre algo muito semelhante, com a ocorrência do mesmo rank para a média dos gastos e da votação, homólogo à hierarquização da titulação escolar. As alterações restringem-se a pequenas diferenças de médias e, conseqüentemente, no rank do custo unitário do voto. No caso, no extremo superior 
do custo do voto, como em geral ocorre, situamse os com curso superior completo (média de $\mathrm{R} \$$ 1 264,80 e erro padrão de R \$ 86,76), seguidos pelos com curso superior incompleto, com o fundamental completo, mas os que apenas lêem e escrevem mantêm-se em uma situação intermediária, enquanto no extremo superior situam-se os com curso fundamental incompleto (média de R\$ 3587,80 e erro padrão de R\$ $633,42)$, seguidos pelos com curso médio completo. Em síntese, mesmo no que tange ao custo unitário do voto há uma forte associação entre a maior titulação escolar e o menor custo, mas isso não é linear.

Para os candidatos a Deputado Federal os resultados são muito semelhantes, com exceção dos que apenas lêem e escrevem. Certamente, isso decorre do fato de tratar-se de uma categoria quantitativamente pouco significativa (apenas oito indivíduos). Em todo caso, no que tange ao rank dos gastos na eleição é o mesmo da titulação escolar, com os que apenas lêem e escrevem no extremo inferior (média de R $\$ 465$ 625,00 e erro padrão de R \$236 634,60), seguidos pela titulação mediatamente acima até o extremo oposto, em que se situam os com curso superior completo (média de R\$ 1291342,00 e erro padrão de $\mathrm{R} \$ 19$ 049,81). No que tange à votação, no extremo superior situam-se os com superior completo (média de 26903,00 votos e erro padrão de R\$ 1063,02$)$, seguidos pelos com curso superior incompleto, mas no extremo oposto situam-se, em primeiro lugar, os com curso fundamental incompleto (média de 5 098,11 e erro padrão de $\mathrm{R} \$ 964,75)$, sendo que os que apenas lêem e escrevem nesse caso ocupam uma posição intermediária. Conseqüentemente, no rank do custo unitário do voto no extremo inferior situam-se os que apenas lêem e escrevem (média de $\mathrm{R} \$ 499,45$ e erro padrão de $\mathrm{R} \$ 304,24$ ), porém com os com curso superior completo na segunda posição. No extremo oposto destacam-se os com curso fundamental completo (R\$ 1790,68 e erro padrão de $\mathrm{R} \$ 242,60)$. Em síntese, fica evidente a forte associação entre o grau de titulação escolar e a média do montante dos gastos e a votação, mas nem sempre essa associação é linear.

Os candidatos a Governador também seguem essas tendências gerais, mas como se trata de um universo muito restrito, várias categorias não chegam a ser estatisticamente significativas, como é o caso dos que apenas lêem e escrevem, com curso fundamental completo e com curso fundamental incompleto, com apenas dois indivíduos cada. Conseqüentemente, no rank da média dos gastos, no extremo superior situam-se os com curso fundamental incompleto (média de R\$ 7550000 e erro padrão de R 7450 000) e os com curso superior completo na segunda posição. No extremo oposto situam-se os com curso médio completo (média de R $\$ 1450667,00$ e erro padrão de R $\$ 726$ 289,10), seguidos pelos que apenas lêem e escrevem. Porém, no que tange ao rank da média da votação, é exatamente o mesmo dos níveis de titulação escolar, com os que apenas lêem e escrevem no extremo inferior (média de 1893,00 votos e erro padrão de $\mathrm{R} \$ 114,00$ ), seguidos sucessivamente pela titulação imediatamente acima até o topo, em que se situam os com curso superior completo (média de R\$ 746421,50 votos e erro padrão de R\$ 140 252,40). Conseqüentemente, quanto ao custo unitário do voto, no extremo inferior situamse os com curso fundamental incompleto (média de $\mathrm{R} \$ 52,87$ e erro padrão de $\mathrm{R} \$ 4,49$ ), seguidos pelos com curso médio completo e superior completo e no extremo oposto os que apenas lêem e escrevem (média de $\mathrm{R} \$$ 863,63 e erro padrão de R\$ 132,88). Ou seja, apesar da falta de representatividade estatística para algumas categorias, a menor correspondência entre a titulação escolar e a média de gastos e da votação nesse caso ocorre também por outras razões, visto que as mudanças de posição abrangem também outras categorias, com representatividade estatística. Apesar disso, as relações entre o grau de titulação escolar e a média do montante de gastos e da votação mantêm-se, com exceção de algumas categorias específicas.

Por fim, os candidatos a Senador, que por tratar-se de um universo mais restrito e com titulação escolar em média mais elevada, somente os graus mais altos são estatisticamente significativos. Ou seja, os que apenas lêem e escrevem (um indivíduo), com curso fundamental incompleto (três indivíduos), com curso fundamental completo (sete indivíduos) e com curso médio incompleto (três indivíduos) são estatisticamente inconsistentes, restando apenas os com curso médio completo, com curso superior incompleto e com curso superior completo. Mais que em qualquer outro caso, nesse o rank da média do montante dos gastos e da 
votação são idênticos e correspondem diretamente à hierarquia da titulação escolar. Os com curso superior completo situam-se no extremo dos maiores gastos e votação, em oposição aos títulos escolares com representatividade estatística mais baixos.

\section{CONCLUSÕES}

$\mathrm{O}$ artigo tem como problema geral as relações entre recursos de posição social e, mais especificamente, a condição ocupacional e a titulação escolar, os investimentos na campanha e os resultados em disputas eleitorais nos diferentes níveis. Como parece ter ficado evidente, há um grau de associação relativamente forte, em primeiro lugar, entre a distribuição por categorias ocupacionais e por titulação escolar com os cargos em disputa e com as chances de sucesso eleitoral. Nessas relações, uma categoria "ocupacional", ou seja, aquela dos que já são titulares de cargos públicos eletivos, ocupa uma posição particular, com muito mais vantagens eleitorais, o que, ao que tudo indica, está associado a uma espécie de carisma de função, além de outros recursos. Em segundo lugar, ocorre um alto grau de associação entre a média do montante de gastos declarados na campanha e da votação obtida. Em terceiro lugar, também fica evidente o alto grau de associação entre o rank da média dos gastos e da votação com a titulação escolar. Sendo assim, não apenas ocorre uma forte correlação entre a quantidade de investimentos na campanha e de votos obtidos, como também é possível demonstrar que essa relação está condicionada por recursos pré-existentes à entrada nas disputas políticas, no caso, a condição profissional e o grau de escolarização. Essas relações são sistemáticas e abrangem todos os cargos em disputa, embora com algumas alterações na posição de categorias ocupacionais ou de titulação escolar.

Mas, apesar de sistemáticas e, geralmente, com base em relações com forte grau de associação, as tendências observadas apresentam um caráter bastante geral. Os próprios dados utilizados, de fontes oficiais e restritas quase somente a alguns indicadores relativos a aspectos mais gerais, não permitem avançar além desse nível mais geral. Isso, no entanto, não diminui a importância da constatação dessas tendências, particularmente em uma situação de escassez de análise desse tipo de problema. Além disso, essa constatação de tendências gerais pode servir de ponto de partida para a incorporação de informações e indicadores mais específicos, seja no que tange às bases sociais dos candidatos, seja ao respectivo trajeto político. Isso, evidentemente, requer a incorporação de outras fontes, mesmo que para tanto seja necessária a utilização de universos empíricos mais restritos.

Odaci Luiz Coradini (coradini@ufrgs.br) é Doutor em Antropologia Social pela Universidade Federal do Rio de Janeiro (UFRJ) e Professor de Ciências Sociais na Universidade Federal do Rio Grande do Sul (Ufrgs).

\section{REFERÊNCIAS BIBLIOGRÁFICAS}

BEST, H. \& COTTA, M. (eds.). 2000. Parliamentary Representatives in Europe 1848-2000: Legislative Recruitment and Careers in Eleven European Countries. Oxford: Oxford University.

BEST, H. \& GAXIE, D. 2000. Detours to Modernity: Long-Term Trends of Parliamentary Recruitment in Republican France 1848-1999. In: BEST, H. \& COTTA, M. (eds.). Parliamentary Representatives in Europe 1848-2000: Legislative Recruitment and Careers in Eleven European Countries. Oxford: Oxford University.
BORCHERT, J. \& ZEISS, J. (eds.). 2003. The Political Class in Advanced Democracies: A Comparative Handbook. Oxford: Oxford University.

CORADINI, O. L. 2007. Engajamento associativo-sindical e recrutamento de elites políticas: tendências recentes no Brasil. Revista de Sociologia e Politica, Curitiba, n. 28, p. 181-203, jun. Disponível em: http:// www.scielo.br/pdf/rsocp/n28/a12n28.pdf. Acesso em: 5.jan.2011.

DOGAN, M. 1999. Les profession propicces à la carrière politique. Osmoses, filières e viviers. 
In: OFFERLÉ, M. (dir.). La Profession politique : XIXe-XXe siècles. Paris: Belin.

GAXIE, D. 1980. Les logiques du recrutement politique. Revue Française de Science Politique, Paris, v. 30, n. 1, p. 5-45, fév. Disponível em: http://www.persee.fr/ a r t i c l e A s P F/ r f s p 0035 $2950 \_1980 \_n u m \_30 \_1{ }_{-} 393877 /$ a r t i c 1 e - r f s p 00035 2950_1980_num_30_1_3938777.pdf. Acesso em: 5.jan.2012.

IHL, O. 1999. Deep Pockets. Sur le recrutement ploutocratique du personnel politique aux États-Unis. In: OFFERLÉ, M. (dir.). La Profession politique : XIXe-XXe siècles. Paris: Belin.

LACROIX, B. 1985. Ordre politique et ordre social. Objetivisme, objetivation et analyse politique. In: GRAWITZ, M. \& LECA, J. (dirs.). Traité de Science Politique : La science politique, science sociale; l'ordre politique. Paris: Presses Universitaires de France.

OFFERLÉ, M. 1999. Professions et profession politique. In: (dir.). La Profession politique : XIXe-XXe siècles. Paris: Belin.

SAWICKI, F. 1999. Classer les homes politiques. Les usages des indicateurs de position sociale por la comprehension de la professionalization politique. In: OFFERLÉ, M. (dir.). La Profession politique : XIXe-XXe siècles. Paris: Belin.

WEBER, M. 1982. A política como vocação. In: . Ensaios de Sociologia. $5^{\mathrm{a}}$ ed. Rio de Janeiro: Guanabara.

1984. Economia y sociedad: esbozo de Sociologia Comprensiva. México: Fondo de Cultura Económica. 


\section{SOCIO-PROFESSIONAL GROUPS, ACADEMIC DEGREES AND ELECTORAL DISPUTE}

\section{Odaci Luiz Coradini}

This article presents results from an analysis of the relationship between social position, financial investment in campaigns and results of electoral disputes at different levels. We have included 2004 municipal elections and 2006 general elections candidates. In order to consider resources emanating from social position, we focus on professional status and academic title. We have also examined the effect of the occupation held prior to assuming elected office. According to our general hypothesis, on the one hand, a process of greater concentration of occupational categories representing higher social position and closely associated with valued academic degrees can be identified as we move up the hierarchy toward more prestigious offices. Furthermore, in electoral disputes the effects of these resources make themselves felt in candidates' chances for success or failure. On the other hand,in addition to resources associated with professions and educational level, where offices are prestigious and chances of electoral success higher, we identify a corresponding increase in the occupational "charisma" linked to candidates' previous professional activities.

KEYWORDS: Elections; Social Position; Social Selection; Academic Degrees; Politics and Charismatic Position; Electoral Processes; Financial Investment. 